\title{
Assisted Breathing with a Diaphragm Pacing System: A Systematic Review
}

\author{
A-la Woo ${ }^{1}$, Ha-jin Tchoe ${ }^{2}$, Hae-won Shin ${ }^{2}$, Chae-min Shin ${ }^{2}$, and Chae-Man Lim ${ }^{1}$ \\ ${ }^{1}$ Division of Pulmonary and Critical Care Medicine, University of Ulsan College of Medicine, Asan Medical Center, Seoul; \\ ${ }^{2}$ Division for New Technology Assessment, National Evidence-Based Healthcare Collaborating Agency, Seoul, Korea.
}

Purpose: Patients with respiratory failure associated with neurological dysfunction often require mechanical ventilator support, which poses increased economic burden and ventilator-associated complications. A diaphragm pacing system (DPS) is an implanted device that provides respiratory support for such patients. In this systematic review, we reviewed the literature to assess the safety and efficacy of DPS for patients with respiratory failure resulting from amyotrophic lateral sclerosis (ALS) or cervical spinal cord injuries.

Materials and Methods: The following databases were searched from July 10 to July 30, 2018: MEDLINE, EMBASE, Cochran library, KoreaMed, Research Information Sharing Service, Korean studies Information Service System, Korea Institute of Science and Technology Information, and Korean Medical database. The abstracts and full texts of the searched articles were reviewed by two reviewers.

Results: The search keywords generated 197 articles: two randomized controlled trials, two case-control studies, and one case report involving patients with ALS; one cohort study, one case-control study, and two case reports involving patients with cervical spine injury; and one case report involving patients with both conditions were included. The primary outcome was safety profile (complications and adverse event) and efficacy (overall survival and sleep improvement). Complications and adverse events were more common in patients with ALS and spinal cord injury receiving DPS than in controls. Efficacy outcomes were inconsistent across ALS studies.

Conclusion: Based on safety and efficacy results, we do not support using DPS to manage respiratory failure in patients with ALS or cervical spine injury.

Key Words: Amyotrophic lateral sclerosis, spinal cord injury, electrical stimulation therapy, diaphragm

\section{INTRODUCTION}

Amyotrophic lateral sclerosis (ALS) is a progressive neurodegenerative disease that affects respiratory muscles and eventually requires respiratory assistance. ${ }^{1}$ Like patients with ALS,

Received: May 11, 2020 Revised: October 5, 2020

Accepted: October 22, 2020

Corresponding author: Chae-Man Lim, MD, PhD, Division of Pulmonary and Critical Care Medicine, University of Ulsan College of Medicine, Asan Medical Center, 88 Olympic-ro 43-gil, Songpa-gu, Seoul 05505, Korea.

Tel: 82-2-3010-6809, Fax: 82-2-3010-6968, E-mail: cmlim@amc.seoul.kr

-The authors have no potential conflicts of interest to disclose.

(c) Copyright: Yonsei University College of Medicine 2020

This is an Open Access article distributed under the terms of the Creative Commons Attribution Non-Commercial License (https://creativecommons.org/licenses/ by-nc/4.0) which permits unrestricted non-commercial use, distribution, and reproduction in any medium, provided the original work is properly cited. patients with cervical spinal cord injury commonly have compromised respiration, causing morbidity and mortality. ${ }^{2} \mathrm{Me}-$ chanical ventilation can be used in those patients to support respiratory function ${ }^{3,4}$ and alleviate sleep disorders. ${ }^{5}$ It is, however, costly, requires continuous monitoring, and is associated with several complications. ${ }^{6,7}$ Hence, clinicians must endeavor to prevent respiratory failure, a major cause of mortality in patients with ALS and spinal cord injury, ${ }^{8}$ while deferring the need for mechanical ventilation as long as possible. ${ }^{4}$

Diaphragm pacing is a technique with a history of over a halfcentury for respiratory assistance. ${ }^{9}$ Diaphragm pacing provides respiratory support by stimulating diaphragm contractions with electrical impulses generated by implanted electrodes (Fig. 1). Diaphragm pacing systems (DPS) using various surgical techniques have been developed. Of these, the United States Food and Drug Administration (FDA) has approved the 


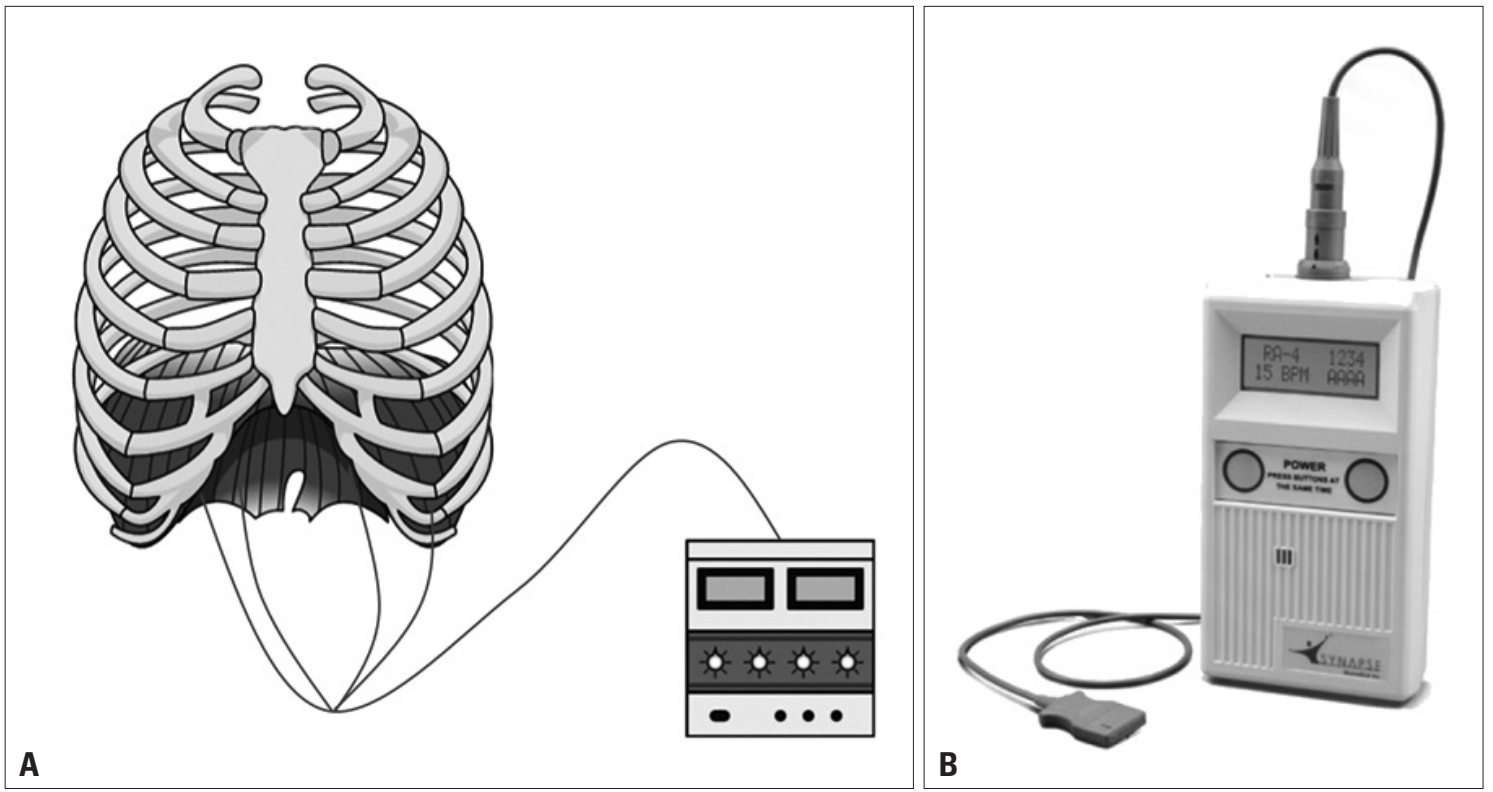

Fig. 1. Diaphragm pacing system. (A) Simplified presentation of a diaphragm system. The electrode is implanted in the diaphragm and connected to the stimulator. The stimulator provides an electrical impulse to the patient's diaphragm, causing it to contract and create respiration. Figure created in the Mind the Graph platform (https://mindthegraph.com/). (B) Image of an actual stimulator device connected to a patient. Adapted from Synapse Biomedical. NeuRx Diaphragm Pacing System ${ }^{\mathrm{TM}}$ : patient/caregiver instruction manual. ${ }^{35}$
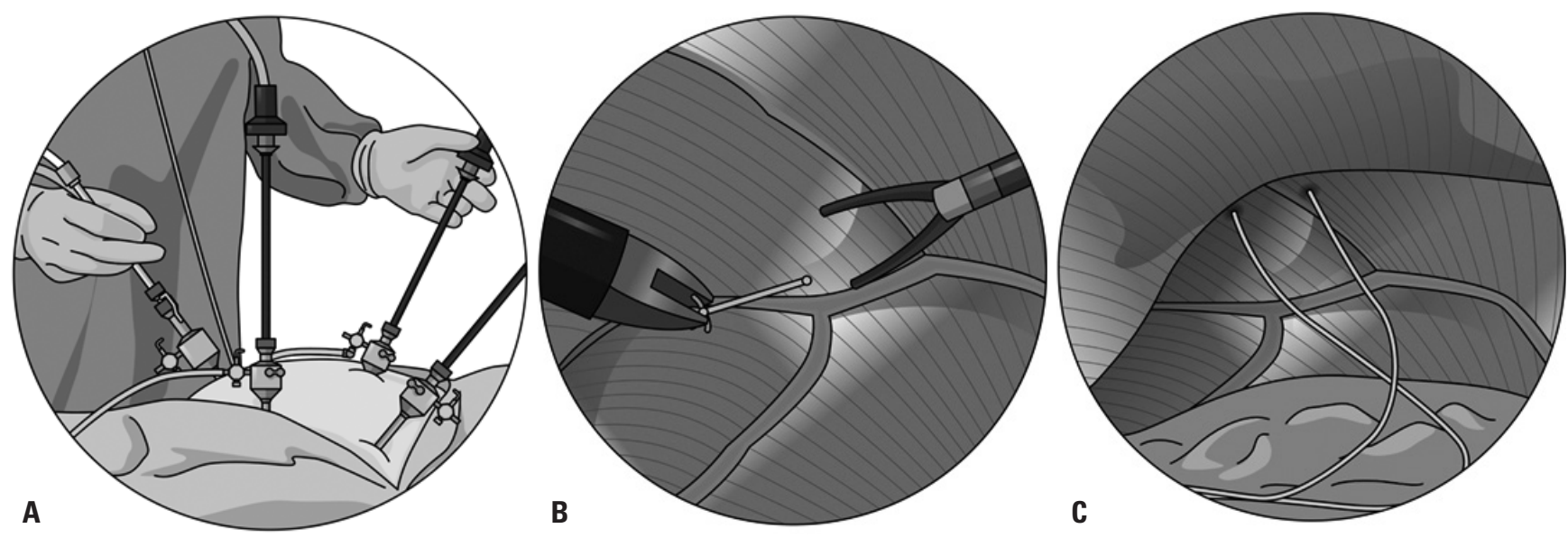

Fig. 2. Implantation procedure for diaphragm pacing. Under general anesthesia, the camera, laparoscopic implant tool, and mapping probes are inserted through four trocars into the patient's abdominal cavity (A). The mapping procedure is achieved by electrical stimulation of the diaphragm with a probe. After mapping of the diaphragm, the electrode is inserted laparoscopically (B). The implanted electrodes in each diaphragm (C). Figure created in the Mind the Graph platform (https://mindthegraph.com/).

following two devices: the NeuRx DPS ${ }^{\mathrm{TM}}$ Diaphragm Pacing System and the NeuRx RA/4 (Synapse Biomedical Inc., Cincinnati, OH, USA), both of which are implanted via laparoscopy. ${ }^{10}$ The implantation procedure includes mapping proper position of the electrode by electrical stimulation of the diaphragm and implantation using a laparoscopic inserting device (Fig. 2). Phrenic nerve function should be preserved to make the diaphragm muscle contract. This stimulation not only provide respiratory support but also may delay respiratory muscle atrophy. ${ }^{11}$ Moreover, with most patients with ALS patients suffering from sleep deprivation, diaphragm pacing may improve their sleep quality. ${ }^{12}$ Nowadays, DPS has been widely adopted for cervical spinal injuries and to manage respiratory dysfunction from neurodegenerative diseases, such as ALS. ${ }^{13}$

As the procedure should be performed under general anesthesia, risks from anesthesia and concerns of procedure-related complications have hindered the use of diaphragm pacing in patients with neurological problems. Moreover, there are questions regarding the clinical efficacy of DPS (survival, respiratory outcome, and sleep parameters). ${ }^{14}$ Thus, multiple studies have sought to investigate the efficacy and safety of DPS in patients with ALS and spinal cord injuries. However, these studies have reported inconsistent results.

This systematic review summarizes the results of studies that 
have reported on the safety and efficacy of DPS in patients with ALS or cervical spinal cord injuries with preserved phrenic nerve function.

\section{MATERIALS AND METHODS}

\section{Data sources and literature search}

The present review followed the Preferred Reporting Items for Systematic Reviews and Meta-Analyses reporting guidelines and included literature written in English and Korean. A literature search was performed from July 10, 2018 to July 30, 2018 using the following databases: Ovid-MEDLINE, Ovid-EMBASE, Cochran Library, KoreaMed, Research Information Sharing Service, Korean studies Information Service System, Korea Institute of Science and Technology Information, and Korean Medical database. The following keywords were used: diaphragm pacing, phrenic pacing, DPS, intramuscular diaphragmatic stimulation, ALS, spinal cord injury, and quadriplegia. The detailed search methods and keywords used for each database are provided in Supplementary Table 1 (only online).

\section{Study selection}

We selected studies in accordance with the Population, Intervention, Comparison, Outcome guidelines, based on our target conditions (ALS and spinal cord injury), intervention (selfbreathing-assisted therapy with a DPS), comparator (sham treatment or mechanical ventilation), and outcome (mortali- ty, ventilator weaning, duration of self-respiration after operation, quality of life, operation time, hospital days after operation, and improvement in respiration).

Studies were excluded if they 1) involved animal or preclinical experiments, 2) were not original articles or were grey literature, 3) were published in languages other than English or Korean, 4) were systematic reviews that used a different methodology from the current review, 5) involved study subjects different from the present study, 6) involved a system other than the DPS, 7) used an implantation procedure other than laparoscopy, 8) did not report a clinical outcome, 9) involved duplicated subjects, 10) were duplicated articles, or 11) were unavailable as original articles.

\section{Study quality assessment}

Study quality was assessed independently by the two reviewers using the methodology check list of the Scottish Intercollegiate Guidelines Networks and reported as a grade (Supplementary Table 2, only online). If there was disagreement between the reviewers, consensus was reached through committee discussion.

\section{Data extraction}

Using a data extraction form (Supplementary Table 3, only online), two independent reviewers extracted the safety and efficacy profiles, the intervention used in the study, the characteristics of the study population, and the study outcomes.

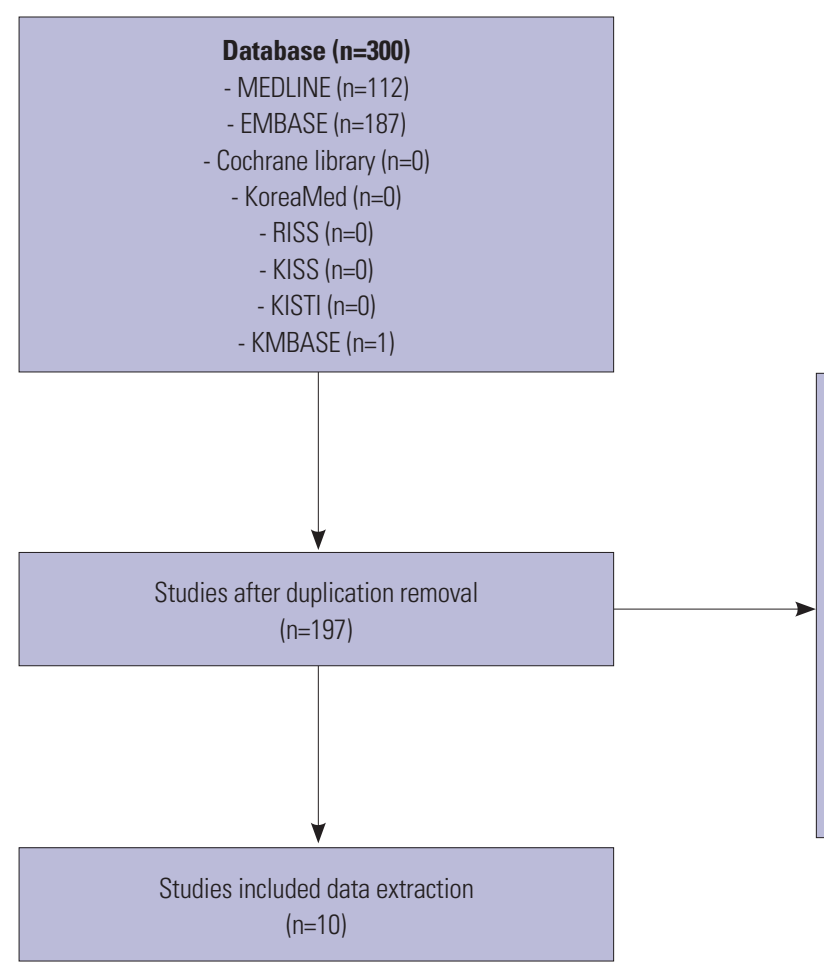

Studies excluded after abstract and full-text review (n=187)

- Involved animal or preclinical experiments $(n=4)$

- Not original articles or grey literature $(n=96)$

- Not published in languages other than English or Korean ( $n=15)$

- Systematic reviews that used a different methodology from the current review $(n=1)$

- Involved study subject different with the present study $(\mathrm{n}=10)$

- Used a system other than diaphragm pacing system ( $\mathrm{n}=22)$

- Used a procedure other than laparoscopy $(n=4)$

- Reported less than one clinical outcome ( $n=27)$

- Duplicated subjects $(n=1)$

- Duplicated articles (n=3)

- Unavailable as original article $(n=4)$

Fig. 3. Flowchart of study selection. RISS, research information sharing service; KISS, Korean studies information service system; KISTI, Korea institute of science and technology information; KMBASE, Korean medical database. 


\section{Data analysis}

The safety (occurrence of complications and adverse events) and efficacy (sleep quality, patient survival, ventilator weaning, and quality of life) results for ALS, spinal cord injury, or both were analyzed by two reviewers using the quality analysis method.

\section{RESULTS}

\section{Study selection}

The overall process of literature search and selection is presented in Fig. 3. In total, 300 articles were identified. After duplicates were removed, the abstract and full text of 197 articles were reviewed. Ultimately, 10 articles were included in the review. Additional details about the included articles and the results of quality assessment are presented in Table 1. Among the reviewed studies, seven studies were non-analytic case reports (level of evidence with 3), one was a cohort study with risk of confounding (level 2-), and two were randomized controlled trials (RCTs) with a high level of evidence (1+).

\section{Safety}

\section{Amyotrophic lateral sclerosis}

Two RCTs, ${ }^{15,16}$ two case reports, ${ }^{17,18}$ and one cohort study ${ }^{19}$ reported procedure-related mortality, complications, adverse events, and/or failure of device implantation in patients with ALS (Table 2, 3). No studies reported a safety outcome as a primary endpoint. Therefore, we compared safety outcomes using the reported complications. In one RCT, ${ }^{16}$ serious adverse events and complications were not significantly different between the intervention (diaphragm pacing with active stimulation) and control (sham stimulation) groups (Table 2). The other RCT ${ }^{15}$ compared patients who received DPS plus noninvasive ventilation (intervention group) with those who received non-invasive ventilation only (control group). The total number of complications was higher in the intervention group than in the control group ( $78 \%$ vs. 3\%). Further, adverse events were more common for all organ systems in the intervention group than in the control group (Table 2). However, although overall complications were more common in the intervention groups than in the control groups, serious adverse events, such as procedure-related mortality, were not reported for either RCT. Failure of device implantation was only reported in one case report.

\section{Spinal cord injury}

Only two cohort studies ${ }^{19,20}$ described the safety outcomes of DPS in patients with spinal cord injury. The safety outcomes were defined as perioperative mortality, complications and adverse events, and failure of device implantation. No perioperative mortality occurred in the study regarding 50 cases. ${ }^{19}$

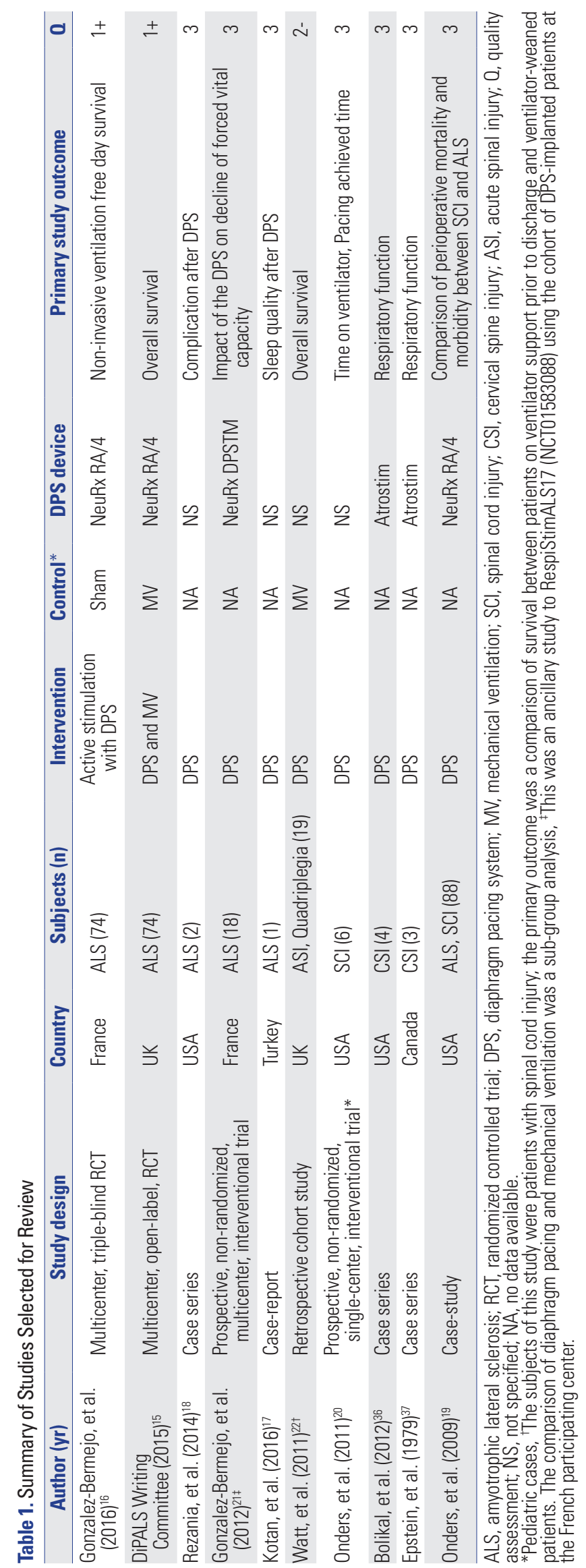


Table 2. Complications and Adverse Events in Randomized Controlled Trials with Amyotrophic Lateral Sclerosis Patients

\begin{tabular}{|c|c|c|c|c|c|}
\hline Author (yr) & $\begin{array}{c}\text { No. of } \\
\text { subjects }\end{array}$ & $\begin{array}{c}\text { Follow-up } \\
\text { duration (yr) }\end{array}$ & Type of complication & $\begin{array}{l}\text { Intervention group (n=37) } \\
(\%, \mathrm{n})\end{array}$ & $\begin{array}{c}\text { Control group }(\mathrm{n}=37) \\
(\text { sham, \%, n) }\end{array}$ \\
\hline \multirow{6}{*}{$\begin{array}{l}\text { Gonzalez-Bermejo, } \\
\text { et al. }(2016)^{16}\end{array}$} & \multirow[t]{6}{*}{74} & \multirow[t]{6}{*}{3.75} & Organ damage during surgical procedure & 0 & $8(3)$ \\
\hline & & & Pneumothorax or capnothorax & $5(2)$ & $5(2)$ \\
\hline & & & Acute respiratory distress syndrome & $19(7)$ & $19(7)$ \\
\hline & & & Venous thromboembolism & $5(2)$ & $3(1))$ \\
\hline & & & Percutaneous endoscopic gastrostomy & $19(7)$ & $24(9)$ \\
\hline & & & Serious adverse event & $59(22)$ & $65(24)$ \\
\hline \multirow{22}{*}{$\begin{array}{l}\text { DiPALS Writing } \\
\text { Committee } \\
(2015)^{15}\end{array}$} & \multirow[t]{22}{*}{74} & \multirow[t]{22}{*}{1} & Respiratory system & $68(25)$ & $38(14)$ \\
\hline & & & Respiratory infection & $35(12)$ & $19(7)$ \\
\hline & & & Respiratory failure & $27(10)$ & $14(5)$ \\
\hline & & & Respiratory distress & $11(4)$ & $5(2)$ \\
\hline & & & Pneumothorax or capnothorax & $14(5)$ & 0 \\
\hline & & & Airway obstruction, pulmonary thromboembolism, cough & $3(1)$ & 0 \\
\hline & & & Pain & $27(10)$ & $16(6)$ \\
\hline & & & Gastrointestinal system & $27(10)$ & $24(9)$ \\
\hline & & & Motoneuron symptoms & $22(8)$ & $8(3)$ \\
\hline & & & Genitourinary system & $8(3)$ & $8(3)$ \\
\hline & & & Dermatologic system & $8(3)$ & $11(4)$ \\
\hline & & & Cardiovascular system & $11(4)$ & $5(2)$ \\
\hline & & & Psychiatric & $11(4)$ & 0 \\
\hline & & & Central nerve system & $3(1)$ & $3(1)$ \\
\hline & & & Insertion or removal of PEG or PIG tube & $14(5)$ & $24(9)$ \\
\hline & & & Infection of PEG or PIG & $8(3)$ & $3(1)$ \\
\hline & & & Wire problems & $14(5)$ & 0 \\
\hline & & & Mechanical ventilation & $8(3)$ & $5(2)$ \\
\hline & & & Infection of wire & $8(3)$ & 0 \\
\hline & & & Other & $5(2)$ & $8(3)$ \\
\hline & & & Total rate of adverse events & $78(29)$ & $3(1)$ \\
\hline & & & Rate of serious adverse events & $73(27)$ & $8(3)$ \\
\hline
\end{tabular}

PEG, percutaneous endoscopic gastrostomy; PIG, per-oral image-guided gastrostomy.

Table 3. Procedure-Associated Mortality and Adverse Events in Cohort Studies of Amyotrophic Lateral Sclerosis Patients

\begin{tabular}{|c|c|c|c|c|c|}
\hline Author (yr) & $\begin{array}{c}\text { No. of } \\
\text { subjects }\end{array}$ & $\begin{array}{l}\text { Follow-up } \\
\text { duration (yr) }\end{array}$ & Type of adverse event & $\begin{array}{l}\text { Number of events } \\
\qquad(\%, n)\end{array}$ & Management \\
\hline \multicolumn{6}{|c|}{ Procedure-associated mortality } \\
\hline Kotan, et al. (2016) ${ }^{17}$ & 1 & 1 & Procedure-related mortality & 0 & NA \\
\hline Onders, et al. (2009)19 & 38 & 7 & Perioperative mortality & 0 & NA \\
\hline \multicolumn{6}{|c|}{ Complications and adverse events } \\
\hline Rezania, et al. (2014) ${ }^{18}$ & 10 & 1 & $\begin{array}{l}\text { Deep vein thrombosis, pulmonary } \\
\text { thromboembolism }\end{array}$ & $20(2 / 10)$ & Warfarin, enoxaparin \\
\hline \multirow[t]{3}{*}{ Onders, et al. $(2009)^{19}$} & 38 & 7 & Wound infection & $2.63(1 / 38)$ & $\begin{array}{l}\text { Oral antibiotics and repositioning or } \\
\text { reinsertion of electrode }\end{array}$ \\
\hline & & & Capnothorax & $13(5 / 38)$ & $\begin{array}{l}\text { Aspiration or observation. No } \\
\text { hemodynamic instability or respiratory } \\
\text { problem }\end{array}$ \\
\hline & & & $\begin{array}{l}\text { Injury to diaphragm, diaphragm laceration, } \\
\text { solid organ damage, bleeding, } \\
\text { bowel injury, conversion to open surgery, } \\
\text { pneumothorax }\end{array}$ & 0 & NA \\
\hline Kotan, et al. $(2016)^{17}$ & 1 & 1 & Failure of device implantation & $0(0 / 1)$ & NA \\
\hline
\end{tabular}

NA, no data available. 
However, wound infection was reported in $2 \%$ of cases, with one study reporting capnothorax in $42 \%$ of cases. ${ }^{19}$ Failure of device implantation occurred $0 \%^{20}$ and $2 \%^{19}$ of the study subjects, respectively (Table 4).

\section{Efficacy}

\section{Amyotrophic lateral sclerosis}

Two RCTs ${ }^{15,16}$ reported the efficacy of diaphragm pacing in pa- tients with ALS. Both studies reported shorter survival in the intervention (with DPS) and control (without diaphragm pacing) groups; there was no significant differences in terms of quality of life (Table 5). ${ }^{15}$ A cohort study reported sleep quality assessment parameters at a median follow-up of 4 months after implantation of the device, ${ }^{21}$ and while there were improvements in some parameters, the Epworth sleepiness score and apnea-hypopnea index were not affected (Table 6).

Table 4. Safety Outcomes of Diaphragm Pacing Systems in Patients with Spinal Cord Injury

\begin{tabular}{|c|c|c|c|c|c|c|}
\hline Author (yr) & $\begin{array}{c}\text { No. of } \\
\text { subjects }\end{array}$ & $\begin{array}{l}\text { Follow-up } \\
\text { duration (yr) }\end{array}$ & Level of spinal injury & Type of event & $\begin{array}{l}\text { Events \% } \\
\text { (n) }\end{array}$ & $\begin{array}{c}\text { Management } \\
\text { of adverse events }\end{array}$ \\
\hline \multicolumn{7}{|c|}{ Procedure-associated mortality } \\
\hline Onders, et al. (2009) 19 & 50 & 7 & High-level, not specified & Perioperative mortality & $0(0 / 50)$ & \\
\hline \multicolumn{7}{|c|}{ Complications and adverse events } \\
\hline \multirow[t]{3}{*}{ Onders, et al. (2009) ${ }^{19}$} & 50 & 7 & High-level, not specified & Wound infection & $2(1 / 50)$ & $\begin{array}{l}\text { Oral antibiotics, repositioning or } \\
\text { reinsertion of electrode }\end{array}$ \\
\hline & & & & Capnothorax & $42(21 / 50)$ & $\begin{array}{l}\text { Aspiration or observation. } \\
\text { No hemodynamic instability or } \\
\text { respiratory problems }\end{array}$ \\
\hline & & & & $\begin{array}{l}\text { Injury of diaphragm, diaphragm } \\
\text { laceration, solid organ damage, } \\
\text { bleeding, bowel injury, conversion } \\
\text { to open surgery, pneumothorax }\end{array}$ & $0(0 / 50)$ & NA \\
\hline \multicolumn{7}{|c|}{ Failure rate of device implantation } \\
\hline Onders, et al. $(2011)^{20}$ & 5 & 1 & C1 (1), C2-C3 (3), C4-C6 (1) & Failure of device implantation & $0(0 / 5)$ & NA \\
\hline Onders, et al. (2009)19 & 50 & 7 & High-level, not specified & Failure of device implantation & $2(1 / 50)$ & NA \\
\hline
\end{tabular}

C, cervical spine; NA, no data available.

Table 5. Efficacy Outcomes of Diaphragm Pacing Systems in Amyotrophic Lateral Sclerosis Patients

\begin{tabular}{|c|c|c|c|c|c|c|c|}
\hline Author (yr) & $\begin{array}{c}\text { No. of } \\
\text { subjects }\end{array}$ & Parameter & $\begin{array}{l}\text { Follow-up } \\
\text { duration (yr) }\end{array}$ & $\begin{array}{l}\text { Intervention } \\
\text { group (months) }\end{array}$ & $\begin{array}{l}\text { Control group } \\
\text { (months) }\end{array}$ & $\begin{array}{c}\text { HR } \\
(95 \% \mathrm{CI})\end{array}$ & $p$ value \\
\hline \multicolumn{8}{|l|}{ Survival } \\
\hline \multirow[t]{2}{*}{$\begin{array}{l}\text { Gonzalez-Bermejo, } \\
\text { et al. }(2016)^{16}\end{array}$} & 74 & NIV free survival since randomization & 3.75 & $6.0(3.6-8.7)$ & 8.8 (4.2 not reached) & $\begin{array}{c}1.96 \\
(1.08-3.56)\end{array}$ & 0.02 \\
\hline & 74 & Overall survival since randomization & & $15.6(9-27)$ & Not reached (>33) & $\begin{array}{c}3.14 \\
(1.31-7.53)\end{array}$ & 0.007 \\
\hline \multirow[t]{2}{*}{$\begin{array}{l}\text { DiPALS writing } \\
\text { Committee }(2015)^{15}\end{array}$} & 74 & Median survival & 1 & $11.0(8.3-13.6)$ & 22.5 (13.6 not reached) & $\begin{array}{c}2.27 \\
(1.22-4.25)\end{array}$ & 0.009 \\
\hline & 74 & Tracheostomy-free survival & & $11.0(8.3-13.6)$ & 22.5 (13.6 not reached) & $\begin{array}{c}2.42 \\
(1.28-4.59)\end{array}$ & 0.007 \\
\hline \multicolumn{8}{|l|}{ Quality of life } \\
\hline \multirow[t]{4}{*}{$\begin{array}{l}\text { DiPALS writing } \\
\text { Committee }(2015)^{15}\end{array}$} & 74 & $\begin{array}{l}\text { SF-36* total physical health average } \\
\text { point }\end{array}$ & 1 & $23.8(12.2)$ & $21.3(12.0)$ & $\begin{array}{c}0.3 \\
(-2.0-2.7)\end{array}$ & 0.789 \\
\hline & & $\begin{array}{l}\text { SF-36 total psychological health } \\
\text { average point }\end{array}$ & & $42.7(16.5)$ & $47.7(17.8)$ & $\begin{array}{c}-3.5 \\
(-7.9-0.8)\end{array}$ & 0.112 \\
\hline & & SAOLI ${ }^{\dagger}$ average point & & $3.9(1.6)$ & $4.6(1.5)$ & $\begin{array}{c}-0.3 \\
(-0.7-0.1)\end{array}$ & 0.117 \\
\hline & & $\begin{array}{l}\text { Caregiver Burden Inventory average } \\
\text { point }\end{array}$ & & $28.0(9.0)$ & $29.6(11.9)$ & $\begin{array}{c}1.2 \\
(-2.7-5.0)\end{array}$ & 0.558 \\
\hline
\end{tabular}

$\mathrm{HR}$, hazard ratio; NIV, non-invasive ventilation; $\mathrm{Cl}$, confidence interval.

${ }^{*}$ Short form-36 is a health status profile used to measure health states of patients, ${ }^{38}{ }^{\dagger}$ the Calgary Sleep Apnea Quality of Life Index, is a questionnaire for recording and evaluating health-related quality of life. ${ }^{39}$ 
Table 6. Sleep and Respiration Outcomes in Amyotrophic Lateral Sclerosis

\begin{tabular}{|c|c|c|c|c|}
\hline Author (yr) & No. of subjects & Parameters & Difference-month 3 to month $7^{\dagger}$ & $p$ value \\
\hline \multicolumn{5}{|l|}{ Sleep improvement } \\
\hline \multirow{14}{*}{$\begin{array}{l}\text { Gonzalez-Bermejo, } \\
\text { et al. }(2012)^{21}\end{array}$} & \multirow[t]{14}{*}{18} & Epworth sleepiness score* $(0-24)$ & $-0.8 \pm 3.1(-2.0)$ & 0.0745 \\
\hline & & Total sleep duration (minute) & $-42 \pm 107(-19)$ & 0.0969 \\
\hline & & Total sleep time (minute) & $26 \pm 104(35)$ & 0.6013 \\
\hline & & Sleep efficacy (\%) & $8 \pm 12(9)$ & 0.0394 \\
\hline & & Sleep incubation period (minute) & $11 \pm 52(5)$ & 0.3829 \\
\hline & & Stage N1-N2 (\% of total sleep time) & $0.1 \pm 12.1(0.9)$ & 0.9229 \\
\hline & & Stage N3 ( $\%$ of total Sleep time) & $1.3 \pm 10.3(4.6)$ & 0.9068 \\
\hline & & REM (\% of total sleep time) & $-1.4 \pm 6.9(-0.5)$ & 0.4748 \\
\hline & & Arousal after sleep (time) & $-59 \pm 73(-69)$ & 0.0032 \\
\hline & & Arousal index (per h) & $-6 \pm 7(-7)$ & 0.0005 \\
\hline & & Apnea-hypopnea index (per h) & $-4 \pm 10(-1)$ & 0.1196 \\
\hline & & REM apnea-hypopnea index (per h) & $-7.4 \pm 15.8(-1.8)$ & 0.045 \\
\hline & & Use of cervical muscle (\% of total sleep period) & $-5.2 \pm 9.3(-3.8)$ & 0.0093 \\
\hline & & Time spent with $\mathrm{SpO}_{2}$ less than $90 \%$ (\% of total sleep period) & $1.4 \pm 4.3(0.0)$ & 0.2661 \\
\hline \multicolumn{5}{|c|}{ Improvement of respiration } \\
\hline \multirow{10}{*}{$\begin{array}{l}\text { Gonzalez-Bermejo, } \\
\text { et al. }(2012)^{21}\end{array}$} & \multirow[t]{10}{*}{18} & ALSFRS-R & $-4.9 \pm 6.1(-1.0)$ & 0.0032 \\
\hline & & FVC (\% predicted) & $-9.4 \pm 10.8(-8.5)$ & 0.0024 \\
\hline & & ERV (\% predicted) & $-14.1 \pm 21.4(-11.5)$ & 0.0134 \\
\hline & & RV (\% predicted) & $-10.3 \pm 21.2(-5.8)$ & 0.0817 \\
\hline & & SNIP (\% predicted) & $-9.1 \pm 8.6(-8.0)$ & 0.001 \\
\hline & & Pi, max (\% predicted) & $-6.1 \pm 16.8(0)$ & 0.351 \\
\hline & & Pe, max (\% predicted) & $-6.3 \pm 7.6(-6.5)$ & 0.0027 \\
\hline & & Pes, twitch with BAMPS $\left(\mathrm{cmH}_{2} \mathrm{O}\right)$ & $-2.5 \pm 3.5(-1.8)$ & 0.0055 \\
\hline & & Pga, twitch with BAMPS $\left(\mathrm{cmH}_{2} \mathrm{O}\right)$ & $-1.4 \pm 2.0(-0.9)$ & 0.016 \\
\hline & & Pdi, twitch with BAMPS $\left(\mathrm{cmH}_{2} \mathrm{O}\right)$ & $-3.6 \pm 4.9(-2.5)$ & 0.0009 \\
\hline
\end{tabular}

REM, rapid eye movement; ALSFRS-R, amyotrophic lateral sclerosis functional rating scale; FVC, forced vital capacity; ERV, expiratory reserve volume; SNIP, sniff nasal inspiratory pressure; $\mathrm{Pi}$, max, maximal static inspiratory pressure measured at the mouth; $\mathrm{Pe}$, max, maximal static expiratory pressure measured at the mouth; Pes, esophageal pressure; BAMPS, bilateral anterior magnetic stimulation; Pga, gastric pressure; Pdi, transdiaphragmatic pressure.

${ }^{*}$ The Epworth sleepiness scale is a subjective measurement of sleepiness; scores higher than 10 points may require medical attention, ${ }^{40}{ }^{\dagger}$ Month 3 was the time of baseline and month 7 was the time of 4 months after device implantation and diaphragm conditioning.

\section{Spinal cord injury}

Only one study ${ }^{22}$ compared overall survival between intervention (diaphragm pacing) and control groups in patients with spinal cord injury. This retrospective study reviewed 25 years of follow-up data for 55 patients with spinal cord injury requiring mechanical ventilation. Of the 55 patients, 19 patients received diaphragm pacing with mechanical ventilation, while the remaining 36 patients received mechanical ventilation only. The overall survival did not differ significantly between groups when stratified by age (Table 7). Mechanical ventilator weaning was successful in 33\% (2/6) and 96\% (48/50) cases in a pediatric case series and an adult prospective cohort, respectively (Table 8).

\section{DISCUSSION}

DPSs assist patient respiration through electrical stimulation of the diaphragm. Several text books ${ }^{23-25}$ have recommended it as a treatment option for respiratory failure in spinal cord injury, ALS, and sleep apnea.

To date, the only known medication that prolongs survival in patients with ALS is riluzole, ${ }^{26}$ but its effects are limited. Therefore, supportive treatments, such as non-invasive mechanical ventilation, for neurological dysfunction are important in ALS management ${ }^{27}$ and can improve patient survival and quality of life. ${ }^{28}$ However, mechanical ventilation is burdensome to maintain; hence, patients can become discouraged to use it consistently. Diaphragm pacing may, thus, be a more attractive option for supportive management of respiration since it is an implantable device that allows more physical activity and mobility than non-invasive ventilation. Although the FDA has approved the use of the technology and promising results have been reported in patients with spinal cord injury, some studies have reported disappointing results in patients with ALS.

Diaphragm pacing has been conducted by different tech- 
Table 7. Overall Survival in Spinal Cord Injury Patients after Diaphragm Pacing System

\begin{tabular}{|c|c|c|c|c|c|c|}
\hline \multirow{2}{*}{ Author (yr) } & \multirow{2}{*}{ No. of subjects } & \multirow{2}{*}{ Follow-up duration (yr) } & \multirow{2}{*}{ Age (years) } & \multicolumn{2}{|c|}{ Mean survival duration, months (No. of patients) } & \multirow{2}{*}{$p$ value } \\
\hline & & & & Intervention group* $(\mathrm{n}=19)$ & Control group $^{\dagger}(\mathrm{n}=36)$ & \\
\hline \multirow{3}{*}{ Watt, et al. $(2011)^{22 \ddagger}$} & & & $0-30$ & $19.2(13)$ & $17.4(12)$ & 0.142 \\
\hline & 55 & 25 & $30-45$ & $3.2(3)$ & $9.9(12)$ & 0.129 \\
\hline & & & $46+$ & $10.3(3)$ & $7.9(12)$ & 0.860 \\
\hline
\end{tabular}

${ }^{*}$ diaphragm pacing (full or part time), ${ }^{\dagger}$ mechanical ventilation only, ${ }^{\dagger}$ Retrospective study of spinal cord injury patients with mechanical ventilation. The comparison was between subjects with diaphragm pacing and mechanical ventilation and those with mechanical ventilation alone.

Table 8. Ventilator Weaning in Patients with Spinal Cord Injury

\begin{tabular}{lcccc}
\hline \multicolumn{1}{c}{ Author (yr) } & No. of subjects & Follow-up duration (yr) & $\begin{array}{c}\text { Level of spinal injury } \\
\text { (No. of patients) }\end{array}$ & $\begin{array}{c}\text { Ventilator weaning, \% } \\
\text { (No. of patients, person/total) }\end{array}$ \\
\hline Onders, et al. (2011) & 6 & 1 & C1 (1), C2-C3 (3), C4-C6 (1) & $33(2 / 6)$ \\
Onders, et al. (2009) & 50 & 7 & NA & $96(48 / 50)$ \\
\hline
\end{tabular}

C, cervical spine; NA, no data available.

*The subjects of this study were pediatric patients.

niques and devices. Moreover, various definitions and measurements of study outcomes have led to inconsistent study results in terms of safety and efficacy. In this systematic review, we aimed to evaluate the efficacy and safety of a technique in which electrodes are implanted into the diaphragm muscle (diaphragm pacing) and provide information to clinicians regarding whether diaphragm pacing should be recommended to patients. Hence, we only included studies that used similar devices and implantation techniques (laparoscopic procedure), had limited target conditions (ALS and spinal cord injury), and assessed well-defined clinical outcomes (efficacy and safety).

The RCT ${ }^{15}$ involving patients with ALS reported that complications and adverse events were higher in the intervention group (with diaphragm pacing) than in the control group (without diaphragm pacing). This was expected in studies, such as the DiPALS study, ${ }^{15}$ where a surgical procedure was only conducted in the intervention group. In the RespiStimALS study ${ }^{16}$ that used a sham surgical intervention in controls, there were no significant differences in respiratory complications or complications related to the surgical procedures (capnothorax or pneumothorax, acute respiratory failure). Overall complication rates were $78 \%$ in DiPALS study (intervention group) and $59 \%$ (active stimulation) and $65 \%$ (sham stimulation) in the RespiStimALS study, which are much higher than that in individuals without a procedure (3\% in DiPALS study). Owing to the already high perioperative and postoperative risks of surgery in patients with ALS, the surgical process of diaphragm pacing implantation may increase the risk of procedure-related mortality and complications. ${ }^{29-31}$

The two cohort studies ${ }^{19,20}$ involving patients with cervical spinal cord injury did not report procedure-related mortality or device implantation failures. Failure of device implantation was relatively low: this may have been related to the physicians' experience and patient volume of the center. However, because of the limited number of studies that were eligible for this review, solid recommendations cannot be made about the safe- ty of diaphragm pacing in patients with cervical spinal cord injury.

Studies involving patients with ALS showed different results than those involving patients with spinal cord injury. Patients in the intervention group (diaphragm pacing) had a shorter survival than those in the control group in both randomized controlled studies. ${ }^{15,16}$ The DiPALS study ${ }^{15}$ included patients with ALS who required non-invasive support due to respiratory insufficiency and showed disappointing overall survival in the intervention group. The RespiStimALS study, ${ }^{16}$ which included patients with moderate respiratory dysfunction who were not requiring non-invasive ventilation, also showed worse overall survival in the diaphragm pacing group. This suggested that the timing of the intervention and residual respiratory functions did not affect the clinical outcome of the studies. Additional analyses of the RespiStimALS data showed that the level of involved neurons did not affect survival outcomes in patients who received a DPS. ${ }^{32}$ The study populations of the RCTs were similar to those of the studies reviewed by the FDA before approving the DPS; however, the efficacy outcomes were different. $^{33}$

Quality of life was not significantly different between patients receiving the DPS plus non-invasive ventilation and those receiving non-invasive ventilation alone. ${ }^{15}$ Sleep improvement was reported in terms of 14 sleep-related variables, five of which showed improvement. ${ }^{21}$ However, the apnea-hypopnea index, the most clinically important indicator, was not significantly different between the intervention and control groups. Furthermore, with regard to respiratory function, forced vital capacity decreased after implantation of the DPS. ${ }^{21}$ Overall, DPS does not appear to have clinical efficacy in patients with ALS.

The studies involving patients with spinal cord injury ${ }^{22}$ found that survival duration was not significantly different between diaphragm pacing and no diaphragm pacing. The rate of mechanical ventilation weaning in patients with spinal cord injury was reported in one cohort study and one case series as $33 \%^{20}$ 
and $96 \%,{ }^{19}$ respectively. However, with regard to quality assessment, given that one study was only a case series, the results remain inconclusive. Additional well-designed studies are required to ascertain the efficacy of DPS in patients with spinal cord injuries.

Garara, et al. ${ }^{34}$ published a systematic review on the safety and efficacy of diaphragm pacing in ventilator-dependent patients with high cervical injuries. They suggested that the treatment was safe because the complications were less severe, the device only required simple management, and the treatment was efficient, allowing the patients to be weaned of the ventilator. Owing to the generally low quality and limited number of subjects in available studies, our systematic review did not reach a firm conclusion that diaphragm pacing in high cervical spinal cord injuries should be accepted as validated management.

A strength of this systematic review was that we included studies using similar intervention techniques (laparoscopic procedure, DPS) to diminish the heterogeneity of results. There are, however, several limitations. First, most of the studies included were not high-level studies with strong methodologies: only two randomized controlled studies were eligible for inclusion in the analysis. Second, because of the overall limited number of studies, some clinical outcomes (e.g., sleep-associated outcomes, overall survival of spinal cord injury) were extracted from a single study. Thus, it is difficult to draw a robust conclusion about the clinical outcomes.

DPS are frequently used as short- or long-term alternatives to mechanical ventilation in patients with ALS. Results from this systematic review, however, suggest that diaphragm pacing recipients experience more complications and adverse events and are less likely to show an improvement in clinical outcomes than non-recipients. Our synthesis of the literature does not recommend the use of DPS to manage respiratory failure in patients with ALS or cervical spinal cord injuries. Further comprehensive studies, including RCTs, are needed to adequately evaluate the efficacy and safety profile of this technique.

\section{ACKNOWLEDGEMENTS}

This research was supported by New Technology Assessment, National Evidence-based Healthcare Collaborating Agency.

\section{AUTHOR CONTRIBUTIONS}

Conceptualization: Chae-Man Lim, Ha-jin Tchoe, Hae-won Shin, and Chae-min Shin. Data curation: Ha-jin Tchoe, Hae-won Shin, and Chae-min Shin. Formal analysis: Ha-jin Tchoe, Hae-won Shin, and Chae-min Shin. Funding acquisition: Ha-jin Tchoe, Hae-won Shin, and Chae-min Shin. Investigation: Ha-jin Tchoe, Hae-won Shin, and Chae-min Shin. Methodology: Ha-jin Tchoe, Hae-won Shin, and Chae-min Shin. Project administration: Ha-jin Tchoe, Hae-won Shin, and Chae-min Shin. Resources: Ha-jin Tchoe, Hae-won Shin, and Chae-min Shin. Software: A-la Woo. Supervision: Chae-Man Lim. Validation: A-la Woo. Visualization: A-la Woo. Writing_original draft:
A-la Woo. Writing —review \& editing: A-la Woo and Chae-Man Lim. Approval of final manuscript: all authors.

\section{ORCID iDs}

$\begin{array}{ll}\text { A-la Woo } & \text { https://orcid.org/0000-0002-8818-6115 } \\ \text { Ha-jin Tchoe } & \text { https://orcid.org/0000-0001-6830-499X } \\ \text { Hae-won Shin } & \text { https://orcid.org/0000-0002-3394-0803 } \\ \text { Chae-min Shin } & \text { https://orcid.org/0000-0001-7970-565X } \\ \text { Chae-Man Lim } & \text { https://orcid.org/0000-0001-5400-6588 }\end{array}$

\section{REFERENCES}

1. Lechtzin N. Respiratory effects of amyotrophic lateral sclerosis: problems and solutions. Respir Care 2006;51:871-84.

2. Lo V, Esquenazi Y, Han MK, Lee K. Critical care management of patients with acute spinal cord injury. J Neurosurg Sci 2013;57:281-92.

3. Berlowitz DJ, Howard ME, Fiore JF Jr, Vander Hoorn S, O'Donoghue FJ, Westlake J, et al. Identifying who will benefit from non-invasive ventilation in amyotrophic lateral sclerosis/motor neurone disease in a clinical cohort. J Neurol Neurosurg Psychiatry 2016;87: 280-6.

4. Clinical indications for noninvasive positive pressure ventilation in chronic respiratory failure due to restrictive lung disease, COPD, and nocturnal hypoventilation--a consensus conference report. Chest 1999;116:521-34.

5. Morelot-Panzini C, Bruneteau G, Gonzalez-Bermejo J. NIV in amyotrophic lateral sclerosis: the 'when' and 'how' of the matter. Respirology 2019;24:521-30.

6. Sancho J, Servera E, Díaz JL, Bañuls P, Marín J. Home tracheotomy mechanical ventilation in patients with amyotrophic lateral sclerosis: causes, complications and 1-year survival. Thorax 2011; 66:948-52.

7. Splaingard ML, Frates RC Jr, Harrison GM, Carter RE, Jefferson LS. Home positive-pressure ventilation. Twenty years' experience. Chest 1983;84:376-82.

8. Corcia P, Pradat PF, Salachas F, Bruneteau G, Le Forestier N, Seilhean D, et al. Causes of death in a post-mortem series of ALS patients. Amyotroph Lateral Scler 2008;9:59-62.

9. Glenn WW, Holcomb WG, Hogan J, Matano I, Gee JB, Motoyama EK, et al. Diaphragm pacing by radiofrequency transmission in the treatment of chronic ventilatory insufficiency: present status. J Thorac Cardiovasc Surg 1973;66:505-20.

10. Gonzalez-Bermejo J, LLontop C, Similowski T, Morélot-Panzini C. Respiratory neuromodulation in patients with neurological pathologies: for whom and how? Ann Phys Rehabil Med 2015;58: 238-44.

11. Onders RP, Elmo M, Kaplan C, Katirji B, Schilz R. Final analysis of the pilot trial of diaphragm pacing in amyotrophic lateral sclerosis with long-term follow-up: diaphragm pacing positively affects diaphragm respiration. Am J Surg 2014;207:393-7.

12. Boentert M. Sleep disturbances in patients with amyotrophic lateral sclerosis: current perspectives. Nat Sci Sleep 2019;11:97-111.

13. Scherer K, Bedlack RS. Diaphragm pacing in amyotrophic lateral sclerosis: a literature review. Muscle Nerve 2012;46:1-8.

14. Arnulf I, Similowski T, Salachas F, Garma L, Mehiri S, Attali V, et al. Sleep disorders and diaphragmatic function in patients with amyotrophic lateral sclerosis. Am J Respir Crit Care Med 2000;161:84956.

15. DiPALS Writing Committee; DiPALS Study Group Collaborators. Safety and efficacy of diaphragm pacing in patients with respiratory insufficiency due to amyotrophic lateral sclerosis (DiPALS): a 
multicentre, open-label, randomised controlled trial. Lancet Neurol 2015;14:883-92.

16. Gonzalez-Bermejo J, Morélot-Panzini C, Tanguy ML, Meininger V, Pradat PF, Lenglet T, et al. Early diaphragm pacing in patients with amyotrophic lateral sclerosis (RespiStimALS): a randomised controlled triple-blind trial. Lancet Neurol 2016;15:1217-27.

17. Kotan D, Kaymak K, Gündogdu AA. Diaphragm pacing system implanted in a patient with ALS. J Back Musculoskelet Rehabil 2016;29:611-2.

18. Rezania K, Gottlieb O, Guralnick A, Prachand V, Sweitzer BJ, Vigneswaran $\mathrm{W}$, et al. Venous thromboembolism after diaphragm pacing in amyotrophic lateral sclerosis. Muscle Nerve 2014;50: 863-5.

19. Onders RP, Elmo M, Khansarinia S, Bowman B, Yee J, Road J, et al. Complete worldwide operative experience in laparoscopic diaphragm pacing: results and differences in spinal cord injured patients and amyotrophic lateral sclerosis patients. Surg Endosc 2009; 23:1433-40.

20. Onders RP, Ponsky TA, Elmo M, Lidsky K, Barksdale E. First reported experience with intramuscular diaphragm pacing in replacing positive pressure mechanical ventilators in children. J Pediatr Surg 2011;46:72-6.

21. Gonzalez-Bermejo J, Morélot-Panzini C, Salachas F, Redolfi S, Straus C, Becquemin MH, et al. Diaphragm pacing improves sleep in patients with amyotrophic lateral sclerosis. Amyotroph Lateral Scler 2012;13:44-54.

22. Watt JW, Wiredu E, Silva P, Meehan S. Survival after short- or long-term ventilation after acute spinal cord injury: a single-centre 25-year retrospective study. Spinal Cord 2011;49:404-10.

23. Ducko CT. Diaphragm pacing. In: Sugarbaker DJ, Bueno R, Colson YL, Jaklitsch MT, Krasna MJ, Mentzer SJ, editors. Adult chest surgery. 2nd ed. New York: McGraw-Hill Education; 2015. p.1214-20.

24. Onders RP. Diaphragm pacing for acute respiratory failure. In: Ferguson MK, editor. Difficult decisions in thoracic surgery: an evidence-based approach. 2nd ed. Springer; 2011. p.329-33.

25. Onders RP. Stimulation for inspiration. In: Krames ES, Peckham PH, Rezai AR, editors. Neuromodulation: comprehensive textbook of principles, technologies, and therapies. 2nd ed. Academic Press; 2018. p.1347-54.

26. Miller RG, Mitchell JD, Moore DH. Riluzole for amyotrophic lateral sclerosis (ALS)/motor neuron disease (MND). Cochrane Database Syst Rev 2012;2012:CD001447.

27. Hobson EV, McDermott CJ. Supportive and symptomatic management of amyotrophic lateral sclerosis. Nat Rev Neurol 2016;12: 526-38.
28. Bourke SC, Tomlinson M, Williams TL, Bullock RE, Shaw PJ, Gibson GJ. Effects of non-invasive ventilation on survival and quality of life in patients with amyotrophic lateral sclerosis: a randomised controlled trial. Lancet Neurol 2006;5:140-7.

29. Short SO, Hillel AD. Palliative surgery in patients with bulbar amyotrophic lateral sclerosis. Head Neck 1989;11:364-9.

30. Pinto S, Swash M, de Carvalho M. Does surgery accelerate progression of amyotrophic lateral sclerosis? J Neurol Neurosurg Psychiatry 2014;85:643-6.

31. Hoeper AM, Barbara DW, Watson JC, Sprung J, Weingarten TN. Amyotrophic lateral sclerosis and anesthesia: a case series and review of the literature. J Anesth 2019;33:257-65.

32. Morélot-Panzini C, Nierat MC, Tanguy ML, Bruneteau G, Pradat $\mathrm{PF}$, Salachas F, et al. No benefit of diaphragm pacing in upper motor neuron-dominant forms of amyotrophic lateral sclerosis. Am J Respir Crit Care Med 2018;198:964-8.

33. US Food and Drug Administration. Humanitarian Device Exemption Database. NeurRx DPS, Diaphragm Pacing System-Summary of safety and probable benefit (no. H100006) [accessed on 2020 September 18]. Available from: https://www.accessdata.fda. gov/scripts/cdrh/cfdocs/cfhde/hde.cfm?id=375558.

34. Garara B, Wood A, Marcus HJ, Tsang K, Wilson MH, Khan M. Intramuscular diaphragmatic stimulation for patients with traumatic high cervical injuries and ventilator dependent respiratory failure: a systematic review of safety and effectiveness. Injury 2016;47:539-44.

35. Synapse Biomedical. NeuRx Diaphragm Pacing System ${ }^{\mathrm{mm}}$ : patient/ caregiver instruction manual [accessed on 2020 September 18]. Available from: https://www.synapsebiomedical.com/wp-content/uploads/2017/09/2017_SCI_Caregiver_Manual.pdf.

36. Bolikal P, Bach JR, Goncalves M. Electrophrenic pacing and decannulation for high-level spinal cord injury: a case series. J Spinal Cord Med 2012;35:170-4.

37. Epstein SW, Vanderlinden RG, Man SF, Hyland RH, Lenkei SC, Wise DJ, et al. Lung function in diaphragm pacing. Can Med Assoc J 1979;120:1360-8.

38. Ware JE Jr, Sherbourne CD. The MOS 36-item short-form health survey (SF-36). I. Conceptual framework and item selection. Med Care 1992;30:473-83.

39. Flemons WW, Reimer MA. Development of a disease-specific health-related quality of life questionnaire for sleep apnea. Am J Respir Crit Care Med 1998;158:494-503.

40. Johns MW. A new method for measuring daytime sleepiness: the Epworth sleepiness scale. Sleep 1991;14:540-5. 